\title{
THE IMPACT OF COOPERATION ON THE IMPLEMENTATION OF THE 'DESCARTE ON' WEEE REVERSE LOGISTICS PILOT PROJECT IN BRAZIL
}

\author{
ERYKA E. FERNANDES AUGUSTO ${ }^{1}$, JACQUES DEMAJOROVIC ${ }^{2} \&$ JOAQUÍN MELGAREJO-MORENO $^{1}$ \\ ${ }^{1}$ Universidad de Alicante, Spain \\ ${ }^{2}$ University Center of FEI, Brazil
}

\begin{abstract}
Accelerated growth in the Electrical and Electronic Equipment (EEE) market, planned obsolescence, and the increase in the disposal of Waste Electrical and Electronic Equipment (WEEE) demand public policies that promote post-consumer responsibility from manufacturers of these products. Europe emerges as an example of WEEE reverse logistics (RL) implementation due to high performance models, which reveal a list of common factors: clear laws, well-defined roles, and coordinated efforts of RL actors to achieve the same goal. These elements of cooperation between the actors can partly explain the success of European countries. However, little research on this theme has been dedicated to understanding the challenges faced by developing countries in the implementation of WEEE RL. This research analyses how cooperation has impacted the implementation and results of a partnership between the Brazilian Government and the Japan International Cooperation Agency (JICA) to implement a WEEE RL pilot project (PP), called 'descarte ON', to assist in the drafting and implementation of the WEEE Sector Agreement (SA). The methodological procedures focus on indepth interviews with multiple stakeholders involved in WEEE RL. Results indicate that the PP showed it is possible to affect RL by means of cooperation among the actors, when there is a proposal that presents opportunities for all actors, with minimised risks, given the appropriate structure to implement partnerships. A favourable aspect was the participation of the retailers in the project, which for many years rejected to join RL initiatives in Brazil. On the other hand, WEEE collections were well below the expected volumes, showing that cooperation has to occur among all RL members including the final consumer. It has been found that the consumer needs to be encouraged and made aware of the benefits of proper disposal, not only in the collection phase but from the discussion and implementation of the project.
\end{abstract}

Keywords: reverse logistics, waste electrical and electronic equipment, WEEE, cooperation.

\section{INTRODUCTION}

The accelerated growth in the Electrical and Electronic Equipment (EEE) market, the programmed obsolescence, and the exponential increase in the disposal of its waste at the end of useful life cycles have generated socio-environmental impacts in all parts of the world, whenever its disposal is not carried out in an environmentally correct way. In 2014, Waste Electrical and Electronic Equipment (WEEE) reached 41.8 million tonnes globally, an increase of $24 \%$ compared to 2010 , while the population grew by only $14 \%$ within the same period. However, of the total WEEE generated in 2014, only 6.5 million tonnes were collected by official collection systems able to monitor their volume and flow and ensure an environmentally correct process. Among the factors that hinder the calculation of data on the rest of the destinations of generated WEEE are the reverse logistics (RL) systems of WEEE in developing countries that are poorly structured, without data management within the process steps, transship for illegal disposal of waste with the aim of externalising recycling costs and have informal RL systems of WEEE in Baldé et al. [1].

Europe emerged on the global stage as an example of the implementation of WEEE RL due to the numbers achieved over the years since the adoption of the 2002 WEEE Directive, 
which sets standards and targets for the correct disposal of WEEE in all EU member countries. The result of the commitment of the member countries in favour of the implementation of the WEEE Directive can be seen in the increase in the collection and recycling of WEEE in Eurostat [2]. In addition, WEEE RL systems in Europe are developing best practices in both production and recycling processes to increase the recyclability of WEEE, exceeding the collection targets imposed by the WEEE Directive (Ylä-Mella et al. [3]).

It is noted that successful European RL models have a list of common elements: partnerships, coordinated efforts, consumer engagement, and information exchange, which strengthens the idea that reverse-chain actors need to be willing to cooperate in the operation of RL [3], Hischier et al. [4], Khetriwal et al. [5], Torretta et al. [6], Wang et al. [7] and Augusto [8]. This research assumes the presumption that WEEE RL programs are complex systems involving multiple actors that need to establish solid and complementary relationships (Vieira, [9]).

The challenges are greater when discussing these issues in relation to developing countries, as their models are still in preliminary stages, and their sociocultural and economic realities are very different. The emerging RL models in these countries are forced to deal with the lack of adequate legislation and economic incentives, low consumer awareness, unbranded products, and unofficial collectors of recyclable materials who are responsible for increasing the collection and processing of WEEE, but who have little concern for health, safety and environmental protection [7], [8].

In Brazil's case, the 2010 National Policy on Solid Waste (NPSW) obliges actors within the EEE sector: producers, importers, and retail companies, to develop and implement WEEE $\mathrm{RL}$ independently from the public waste management system. The law foresaw this model being implemented through a Sectoral Agreement (SA), involving manufacturers, suppliers, and recyclers in a system of shared responsibility (Brasil [10]). Nevertheless, the legislation has not been implemented due to a series of barriers presented by the private sector. Within this scenario, in which the disputes revolve around the viability of the goals imposed by the government, RL operational costs, and conflicting laws, a partnership between the Federal Government of Brazil (FGB) and a Japanese agency proposed to create a pilot project to collect the necessary data and point out the main points that should be changed or inserted into what has been put together so far by the SA. The project was funded and executed by the Japan International Cooperation Agency (JICA) and cooperatively involved the actors of the Federal, State, and Municipal Governments, as well as all EEE sector representatives. In this way, the objective was to understand how cooperation is impacting the implementation of WEEE RL in the Brazilian scenario. In that context this research contributes to the understanding of what the motivational factors are to establish partnerships for the implementation of WEEE RL, and how the planning and structure can facilitate its implementation and the signing of the SA.

\section{THE FACTORS OF COOPERATION}

Cooperation has been recognised as an essential element for the effectiveness of complex systems with multiple actors, both in the environment of public policy [9] and in the implementation of business strategies (Winckler and Molinari [11]). Thus, studies on cooperation emerged in the early nineteenth century, to investigate how associations between firms can generate a competitive advantage, either in the form of collaborative consumption to gain scale, or the financing of joint practices (Drury [12]) with the objective of helping one another with purchasing, credit, distribution channels, exchange of market information, and technological development, among other things (Gault [13]). In the 1930s, cooperation 
gained status as a School of Cooperative Economics in the United States [12]. Throughout the twentieth century, research on its characteristics and benefits intensified along more diverse lines, and in the 1990s the concept of cooperation was consolidated as a strategic element to ensure competitive advantage (Kolbus [14]). Few studies, however, have addressed this issue within the scope of RL, and especially when discussing programs involving WEEE. In order to understand its potential positive impact on the RL of WEEE, this study seeks to consider the main characteristics and fundamental elements for its implementation into the theme.

Cooperation is based on the need or desire to do something with another organisation, on the need to meet market demands, or to contribute to a project, in order to obtain an advantage, based on the organisational objectives for implementing alliances (Polenske [15], Da Silva [16], Winckler and Molinari [11]). The company assumes that the partnership will bring it an advantage or allow it to perform a task, which if acting alone would not be possible (Hord [17]), and it starts the process of identifying potential partners with asymmetric and complementary competencies [11], [15], [17]. The expected results are defined previously [11], [15] in such a way that it meets the collective needs [11]. In this way, each actor is clear on the tangible and intangible benefits that the partnership will bring [11], [15].

The cooperative process, however, does not exclude competitiveness among the actors. For example, a group of manufacturers of a given sector can meet to implement a service, without affecting the competitiveness between them [17]. The companies cooperate in order to compete with others outside the partnership [16]. In this form of relationship, the actors do not work together in an activity, but in a complementary and linked way, with each actor completing the task of the other [11], [15], [17]. Financial, physical, or human resources are not shared, since each actor acts within his own company. It is also possible to create an organisation, such as a cooperative, to share production costs, gain scale, and reduce costs in the overall process [15].

In this scenario, each partner is co-responsible for the product and success of the operation, since all have access to the results of the cooperation [15], and the relationships are external [15], horizontal [11], [15] and non-exclusive [15]. Although the relationships occur in the horizontal sense [11], [15], leadership is usually unilateral, exercised by the company that leads the process, but management remains focused within the organisations [15], [17].

Clarity of processes, alignment of expectations, and formalisation of roles and outcomes increase trust among stakeholders by reducing the amount of effort and time spent on the establishing and maintenance of cooperation [15], [17].

The literature review allowed us to compile the attributes that affect cooperation, dividing them into three dimensions: motivation, scope, and structure, as presented in Table 1.

Thus, it can be seen that organisations cooperate when resources are scarce, strong demand forces it, or their performance is at risk [17], causing them to seek strategic alliances to survive in the global market [15]. The interest is to operationalise a process, step, or service, allowing access to the market, or use of idle capacity of production and cost sharing, without compromising the company's sovereignty [11]. In view of the definition of the attributes that enable cooperation to take place, it is possible to understand how some countries have developed WEEE RL systems that are so effective and perform well beyond the targets set by the WEEE Directive.

\section{IMPACT OF COOPERATION IN WEEE RL}

$\mathrm{RL}$ is the process of planning, implementing, and control of the cost effective and efficient flow of raw materials, in-process inventory, finished goods, and related information from the 
Table 1: Dimensions and attributes of cooperation. (Source: developed by the authors.)

\begin{tabular}{|l|l|}
\hline \multicolumn{1}{|c|}{ Attributes } & \multicolumn{1}{c|}{ Dimension: Motivation } \\
\hline Necessity & The need to do something complex, beyond your skills or resources. \\
\hline Opportunity & $\begin{array}{l}\text { The realisation that there are other actors in the field that can facilitate } \\
\text { implementation or improve results by acting together. }\end{array}$ \\
\hline Willingness & $\begin{array}{l}\text { Partner relationships are evaluated as possible and positive, despite } \\
\text { their complexity, and the actor is willing to interact with others. }\end{array}$ \\
\hline \multicolumn{1}{|c|}{ Attributes } & \multicolumn{1}{c|}{ Dimension: Scope } \\
\hline Nature & $\begin{array}{l}\text { Operationalisation of processes, services, or the improvement of } \\
\text { something. }\end{array}$ \\
\hline Objective & Clear, individual. Need not be the same for each. \\
\hline Results & $\begin{array}{l}\text { Expected outcomes are clearly defined, divided as agreed, and } \\
\text { reported to all to allow learning. }\end{array}$ \\
\hline Actors & May even be competitors. \\
\hline \multicolumn{1}{|c|}{ Attributes } & Dimension: Framework \\
\hline Activity & $\begin{array}{l}\text { Clear division of roles, individually worked on, each actor offering its } \\
\text { best attribute or can create an organisation to execute it. }\end{array}$ \\
\hline Resources & Belong to whoever is performing the task. All parties invest. \\
\hline Communication & Few face-to-face meetings, periodic reports, email. \\
\hline Authority & Management stays focused within each organisation. \\
\hline Control & Formal control mechanisms (signed contracts and agreements). \\
\hline Risk & Divided. Each party assumes its share. \\
\hline
\end{tabular}

point of consumption to the point of origin, with the purpose of recovering value or environmentally appropriate disposal.

Remanufacturing and reconditioning activities may be included in the process (Rogers and Tibben-Lembke 18]). In this way RL is characterised by a set of linked tasks, with a contrary flow to the supply chains, and the end user being the agent that initiates the process [8].

In this context, an effective WEEE RL system requires the coordinated actions of the actors involved within all stages and should be governed by clear laws [6]. This begins with collection, demanding expansion and mobility of discard points, as well as an attitude of conscious discard from the consumer, coordinated with transport, pre-processing, recycling, and environmentally correct destinations (Demajorovic et al. [19]). Since the enactment of the European WEEE Directive, there has been a significant increase in the collection of WEEE. In the case of countries that already had national laws on WEEE and RL systems, national legislation was adapted to align their outcomes with the objectives of the Directive [3]. Government efforts are not limited to legislating in favour of the common objective of serving the Directive, but rather to also actively participate in the collection system, as in Italy, Sweden, Norway and Finland [3]. The government also acts in environmental education and in the creation of incentives for proper disposal so that the collection becomes efficient, meeting the objectives of the EU WEEE Directive, as was the case in Romania [6]. Another characteristic of these successful models is the way WEEE systems are organised since they are generally managed by Producer Responsibility Organisations (PRO) created by manufacturers to ensure system efficiency [3]-[5].

The EU results reveal a list of countries that have implemented high performance models, which have common factors in the implementation and maintenance of WEEE RL. Clear 
laws with well-defined roles and the coordinated efforts of reverse-chain actors to achieve the same goals allow for the greater expansion of collection points (Sinha-Khetriwal [20]). According to Lau and Wang [21], working together is essential in reducing the resilience of business sectors to starting RL programs, due to the high costs involved. Other important factors are the level and awareness of citizens [3], [8], and communication and education about the correct disposal of WEEE [3]. The model introduced in Switzerland is now a reference for Europe, being that it is possible to relate some of its main characteristics to the attributes of cooperation.

\subsection{The Swiss model and the role of cooperation.}

Concern over the accelerated growth and environmental impacts of poor waste management motivated Switzerland to begin a process of reflection on the prerequisites for environmentally sound waste management in the 1970s. Environmental issues, such as the risks generated by consumption, strengthened by the purchasing power and the high level of awareness of Swiss consumers, acted as motivating factors and as a guide to the efforts of government and society in the search for solutions and processes of mitigation [20].

With this in mind, organisations began to anticipate laws and seek solutions for the management of waste resulting from their production and consumption processes, and from the sale and end of life cycle of their goods. In the 1990s, two PROs for managing WEEE in Switzerland, the Swiss Foundation for Waste Management and the SWICO Recycling Guarantee, both voluntary initiatives of the EEE sector, were created. A PRO is the result of a cooperative effort of the industry to assume the responsibilities of its associated companies and fulfil its obligations as defined by the Extended Producer Responsibility (EPR) operationalised throughout WEEE RL [5], [20]. With the two initiatives in operation, Switzerland became the first country to have a formal large-scale WEEE RL system in the world, covering the EEE from these voluntary initiatives of its manufacturers.

An Advanced Recycling Fee (ARF) that facilitates the recycling collection system funds both initiatives. The ARF is charged to the consumer at the time of purchase of the EEE, is specified and highlighted on the receipt, and passed on by the retailers to the PRO [4]. The amounts for the ARF for each product are defined by the PRO [5].

All the management is implemented by the PROs, SWICO, and the SENS Foundation, in a cooperative way, and managed by a committee of representatives for the producers. The PROs are responsible for defining the prerequisites and contracting the system service providers [5]. Each provider is responsible for the transformation of the type of waste to which they are assigned, but in the collection and transportation stages, they increase capacity, reduce transport costs and improve logistics, and work together and gain scale by acting in common collection points. In this way, they guarantee the clear definition of roles and responsibilities, important in relationships of cooperation, and offer to their best attribute to the partnership.

Another advantage of this cooperative relationship is to the consumer, who benefits from the option of multiple common collection points. In 2005, there were more than 500 PRO points and thousands of retail outlets that were required to receive all types of electronics at no cost to the consumer and without excluding brands, types of EEE, or products purchased prior to the establishment of the ARF [20]. The retailer is responsible for receiving the ARF and transferring it to the industry, by passing it on to the PRO. Another task of the retail stores is to do the first sorting, separating what can be reused for remanufacturing, or for second-hand sales as complete items or parts, and what goes straight to dismantling and 
recycling, being that this actor is the only one with the prerogative of separating and selling WEEE that has been disposed of in their establishments [5].

One of the concerns of the Swiss model was also to establish an ARF that is easy to understand by the consumer, transparent in its administration, and that does not generate a cross-subsidy so that products with different degrees of complexity of recycling pay equal amounts, burdening the consumer and generating scepticism towards the system. In addition, recyclers and PROs maintain transparent contract procedures, supervised by regulatory agencies [20]. Thus, the adopted model presents the attributes necessary for the building of trust in cooperative systems based on transparency and monitoring mechanisms [15], [17].

The success of the collection system is due to the cooperative efficiency of the waste flow management of SWICO and SENS. The WEEE collection numbers corroborate the efficiency of process management. In 2003, 68,000 tonnes of WEEE were collected in Switzerland, around $9 \mathrm{~kg} /$ person, $125 \%$ more than the minimum $4 \mathrm{~kg} /$ person required by the EU WEEE Directive [20]. With the entry of the Swiss Lighting Recycling Foundation (SLRS) in 2005, a PRO responsible for lamps and luminaires, the scope of WEEE and the quantitative results were expanded. In 2015, these values almost doubled, reaching approximately 134,000 tons of WEEE collected (SENS [22]).

Another essential element for the success of the RL of WEEE is the waste management system based on Extended Producer Responsibility (EPR) [5]. Although the responsibility for the operation of the system lies with the manufacturers, the co-responsibility of the other actors in the chain is clearly defined by the law, which assigns the role of each one in order to ensure that WEEE returns to collection centers. The government has the role of monitoring the system and licensing activities, as in the case of recycling companies. The case of WEEE RL in Switzerland shows the importance of cooperative partnerships in the operation of the system, attested by its results being well above the European average, with gains in scale, costs, streamlining of resources, expansion of collection points, and better environmental results. Their relationships are well established and anchored in monitoring mechanisms. The roles of each actor are set with the rights and responsibilities of each, including the consumer. These results are possible because the system meets all the essential attributes for the implementation of cooperation, as presented in Table 1. It also shows the positive results of the voluntary initiatives of some EEE industries in the formulation and implementation of a collection system and recycling of WEEE. In this case, a small group of large companies that decided to cooperate to mitigate the impacts resulting from their operations, met the demands of the market, society, and the environment, and was able to motivate the rest of the sector to join the system. However, Switzerland is not alone in developing PROs because there are similar cases in Sweden, Belgium, Norway, and the Netherlands, where EEE producers have established collection systems before their governments have [5].

\section{METHODOLOGY}

As this is a fairly recent phenomenon in literature and little researched in the academic field, a qualitative exploratory and interpretive approach was chosen to study the relationship of cooperation and the RL of WEEE.

As a research strategy we chose to carry out a case study. For Yin [23], a case study is appropriate for situations that remain mostly unexplored in theory, and when the case chosen is unique. 'descarte ON' fulfils these characteristics, as it is the first operational initiative of WEEE RL in Brazil involving the public and private sector.

The primary data was collected through in-depth interviews and observation of the dynamics of the groups that make up the cooperative project between the FGB, the Government of Japan, the Municipality of São Paulo, the Government of the State of 
Table 2: Categories of analysis. (Source: developed by the authors.)

\begin{tabular}{|c|c|c|c|}
\hline Motivation & Attributes of scope & $\begin{array}{l}\text { Attributes of } \\
\text { structure }\end{array}$ & $\begin{array}{c}\text { Impact of } \\
\text { cooperation }\end{array}$ \\
\hline $\begin{array}{l}\text { To highlight the } \\
\text { factors that motivated } \\
\text { the building of } \\
\text { partnerships between } \\
\text { the actors of 'descart } \\
\text { ON' and the motives } \\
\text { for overcoming its } \\
\text { challenges [15], [17]. }\end{array}$ & $\begin{array}{l}\text { To understand how } \\
\text { the scope of the } \\
\text { project was } \\
\text { conceived and } \\
\text { perceived by each } \\
\text { actor, with its } \\
\text { objectives, results, } \\
\text { and included } \\
\text { partners [11], [15], } \\
{[17] .}\end{array}$ & $\begin{array}{l}\text { To describe the } \\
\text { structure and } \\
\text { management of } \\
\text { resources in the } \\
\text { execution of } \\
\text { 'descarte ON'. To } \\
\text { understand how the } \\
\text { structure impacted } \\
\text { its effectiveness } \\
\text { [11], [15], [17]. }\end{array}$ & $\begin{array}{c}\text { To understand } \\
\text { how cooperation } \\
\text { helped the results } \\
\text { of 'descarte ON', } \\
\text { and also how its } \\
\text { absence acted as a } \\
\text { barrier to better } \\
\text { results [3]-[5], } \\
{[20] .}\end{array}$ \\
\hline
\end{tabular}

São Paulo (GSSP), and the representatives of the associations that are required to execute WEEE RL in Brazil, including manufacturers, trade, and recyclers.

For data processing, the research used the technique of content analysis, due to its flexible nature of the use of different techniques for the processing of collected data (Bardin [24]). A central element for performing content analysis is the construction of the categories of analysis. To this end, four categories were defined, which underlay the construction of the data collection instruments in the interviews, as well as in the reading of official documents and field observations in the project meetings attended by the researchers. Table 2 presents the categories and explains their purpose.

\section{PRESENTATION OF RESULTS AND DISCUSSION}

The presentation of the results was elaborated according to the categories defined in the methodology, so that it was possible to understand the factors that motivated the cooperation among the actors involved in the Pilot Project (PP) of WEEE RL. The interviewed actors were identified by the following acronyms: JICA (JC); Federal Government (FG); State Government (SG); Municipal Government (MG); Producers and distributors of EEE, (PD); Retail Trade (RT); Recyclers and Cooperatives of Collectors of Recyclable Materials (RC).

The first category analysed focused on the motivation of the actors in their participation in the PP. In order to guarantee their effective participation, it is important to first understand the factors that motivate the actors to act in the partnership [15], [17]. In the case of this PP, the initial motivation was due to the need to make the RL of WEEE feasible in Brazil by means of the SA, due to the lack of knowledge accumulated by the actors of the reverse chain of EEE in the operationalisation of RL in Brazil. According to the FG, the government prioritised the development of the Brazilian model by means of the SA with the expectation of having the collaboration of the actors involved in the EEE life cycle, and that only as a last resort will the FGB unilaterally define the RL of this sector by means of a decree. However, since the adoption of the NPSW in 2010 little progress has been made in the elaboration of the SA, as actors in the EEE sector have raised a number of barriers. Among the main barriers highlighted are conflicting laws, a tax system that does not encourage the reuse of WEEE, the operational costs of RL, and the goal of collecting $17 \%$ of the EEE volume placed on the market two years earlier [8], [19]. Since most of the challenges pointed out are based on projections of RL costs and estimates of WEEE collections, and not on the practical results of the operationalisation of RL in Brazil, there was a need to collect real data. The Brazilian government, through the Ministry of Industry, Foreign Trade and Services (MIFTS), asked 
Japan to implement a technical cooperative project to be carried out by JICA in order to create the Pilot Project (PP), and thus, based on the analysis of the results of the PP, to achieve consensus among the actors of WEEE RL to sign the SA, according to JC2 and JC4.

The need to create the PP was perceived as an opportunity to collect real data for all actors involved in the EEE SA, since the SA would have to be signed at some point. For the private sector, the fact that the project measured the operational costs of the RL of WEEE, surveyed the real collection potential, and gauged consumer behaviour in relation to disposal was fundamental to showing that the initial RL goals demanded by the government were overambitious (CV1, PD1, PD2). In addition, the financial risks for these actors to acquire such knowledge were negligible, since the entire project was financed by JICA, facilitating the decision of all to participate cooperatively (CV1, GE1, GM1, PD1, PD2, RC1, RC2). From the FGB to the recycling companies, everyone wanted to learn from the Japanese experience. In addition to empirical knowledge, JICA has a strong vocation to transfer knowledge accumulated within the country's own experience and others obtained in cooperative projects to developing countries and could help to solve the various conflicts of the Brazilian actors involved in the negotiation of the WEEE RL SA. Japan also sees opportunity in this partnership, with the potential for generating WEEE in Brazil which can supply its urban mining plants, as well as the creation of new markets with the insertion of small and medium Japanese companies in the Brazilian WEEE market. Thus, the PP managed to align the interests of Brazilian and Japanese actors with the partnership. It is essential that all peers have an interest and realise the importance and opportunities in jointly executing an action, so that these elements outweigh the complexity of cooperative relations [15], [17]. However, an essential actor to WEEE RL was not included in the project, that being the final consumer responsible for the beginning of the reverse chain.

In the 'Scope' category we sought to understand what it was, how the project was conceived, and how it would meet the expectations of each actor in order to establish an observation on the importance of the scope of the project to the results of the cooperation.

The PP was implemented in the city of São Paulo, in the region of Lapa, with the purpose of collecting residential WEEE, excluding batteries. The duration of the project was 3 years, starting in October 2014 with its completion in September 2017. The purpose of the PP was to present a plan to improve the implementation of RL (JC4). According to JICA members, this goal was divided into two macro objectives. The first was to collect data on costs, management, ways of collecting, and what the most appropriate modes for effective disposal are in Brazil's case. The second was to make the population aware of the importance of discarding WEEE (JC2). The industry's players had already wanted to verify how RL would work in Brazil and obtain knowledge of this market (PD1). Retailers needed to understand how their performance as a collection point would impact their business (CV1; CV2). Some of the players in the recycling industry wanted to show that they had the competence to operate in this market (RC1, RC2). It can be seen that in this case the PP met the individual objectives, and this is an important element of cooperation.

The project's results were all pre-set in the initial contract and delivered as agreed to each party. Throughout the implementation monthly meetings were held to discuss the results obtained and plan corrective actions or new strategies when necessary (RC2). At the end of the project, JICA analysed and compiled all the data in the completion report, which suggested some guidelines for the elaboration of the SA (JC4).

In this case public and private actors, represented by their associations and including actors from within the same sectors, were able to participate in the PP as partners, with the objective of implementing the pilot project in a cooperative way (RC3). The companies to implement the communication and RL were selected by notices from JICA. However, some 
of the actors that operated in the PP were invited at the suggestion of other members of the group, as was the case of Coopermiti, a waste collectors' cooperative specialising in WEEE, after demonstrating that it met the required competencies. It participated in all stages, including training and meetings given in Japan (GM1), despite this type of organisation not exist in Japan ( $\mathrm{JC} 1)$.

In the 'Structure' category the characteristics of the implementation of the PP were discussed. The results demonstrate that both the project's scope and structure were well delimited. All actors had their roles previously defined with divisions of activities. FGB, MIFTS and the Ministry of the Environment (ME) participated in the strategic planning, together with JICA. The Municipal Authority of Urban Cleaning (MAUC) participated at the municipal level. GSSP, through the Environmental Control Company of the State of São Paulo, was responsible for issuing the necessary licenses to the PP, and the adviser in light of state laws. The retail associations helped to broker the inclusion of retailers in the Lapa region that participated as collection points. For that purpose, space was provided in those stores for collection boxes and a 'Home Collection' service was tested, which offered the collection of large EEE, for those who bought new equipment for a subsidised amount of $\mathrm{R} \$ 10.00$. Coopermiti acted as Consolidation Center (CC), providing the primary transportation from the stores to its headquarters. However, some retailers were slow to participate because they depended on adaptations to the project that respected the characteristics of their brand. The recycling company Oxil carried out the secondary transportation, processing and allocating an adequate destination for the WEEE. The RL company GM \& $\mathrm{C}$ was responsible for the entire reverse cycle of large EEE from the 'Home Collection'. The EEE industry associations were responsible for monitoring and inspecting the recyclers, along with JICA, and cooperating in publicising the PP on their websites and magazines (RC2). Consumers were to discard their WEEE at the collection points distributed among the retail stores or request the withdrawal of large EEE from the 'Home Collection' service.

With regard to exchange of information, this occurred at monthly meetings, through reports, and with the exchange of e-mails. Any action that any of the actors wanted to perform needed to be evaluated by the JICA team, just as any changes or revisions to what had already been designed were brought up for discussion at meetings, but the final decision was with JICA and the federal government (JC1). The contracts and minutes of meetings worked as a monitoring mechanism, and the structure defined for the PP minimised the risks of each of the partners.

The category 'Impact of Cooperation' sought to understand how the building of partnerships impacted on the results of the project. It can be seen in the results analysis that all the attributes of cooperation were met by the PP, as compared with the elements presented in the literature. The motivation of all the actors to participate, the clarity of what would be executed by the PP, and the clear definition of the roles of each actor stand out in the effectiveness of the cooperation. In addition, the signed contracts, meetings, and periodic reports ensured transparency within the process, providing security to the members of the PP as well as functioning as monitoring mechanisms. In this way, each member contributed its best attributes to the success of the PP, which is another striking feature of cooperation (JC1, $\mathrm{RC} 2$ ). However, despite the effectiveness of the cooperation between the actors who signed the partnership in the PP, the results of the WEEE collections in the stores were much lower than the projections made by JICA, being around $2 \%$ to $3 \%$ of the estimated amount at the collection points, and less than $1 \%$ for the 'Home Collection' service. One of the factors pointed out to explain the result of the 'Home Collection' service was the charge of the symbolic value of $\mathrm{R} \$ 10.00$ for the collection of large WEEE (JC4). According to members 
of the PP, consumers are not motivated to carry out the disposal because they perceive neither the need nor the benefit of the correct disposal of WEEE. In order for this link in the chain to participate cooperatively, it will be necessary that they initially receive incentives to dispose of much of the large WEEE, such as with medium and small equipment. Prominent awareness campaigns also need to be created specifically for this audience. This finding is supported by the data collection, which rose significantly in November and December with the massive campaign to publicise Black Friday and encourage the disposal of WEEE. Other results of the PP point to the importance, in the future, of strengthening the cooperative relations between manufacturers and retailers to create mechanisms of incentives to reach the collection targets. The PP also showed the importance of cooperation among state governments to create a trans-regional recycling zone due to the continental dimensions of Brazil, and due to current recycling centers being concentrated in the southeast region.

The actors within JICA emphasise the importance of cooperation in their implementation of the PP, and add that without it, it will not be possible to implement shared responsibility or implement the RL of WEEE in Brazil.

\section{CONCLUSION}

Significant growth in the EEE market indicates the increasing importance of improving WEEE RL models to ensure its proper and safe disposal. This research shows that in addition to legislation making the actors of the production chain responsible for the operationalisation of this system, cooperation among the stakeholders is essential to guarantee its effectiveness. The Swiss model, for example, shows that competing firms tend to mutually benefit when developing cooperative systems for implementing RL models including other members of the reverse chain, the government, and consumers. However, in developing countries the reality is more challenging, either because of weaknesses in legislation and enforcement, or because of the low availability of WEEE reverse chain members to work cooperatively in the development of RL solutions. The analysed case reaffirms these difficulties by demonstrating the slowness and resistance of members of the EEE chain in implementing RL through a SA, based on a cooperative constructed in order to comply with Brazilian legislation.

The PP showed that it is possible to affect RL by means of cooperation among the actors, when there is a proposal that presents opportunities for all actors, with minimised risks, given the appropriate structure to implement partnerships. Well-defined roles and responsibilities, and trust among members, built through monitoring mechanisms such as contracts, meetings with minutes, widely disseminated periodic reports, and data verification, formed a framework that encouraged everyone's participation, each of whom contributing their best attribute and being assured that they would receive the expected results. A set of attributes essential to cooperation can be seen in the PP, which in short time was able to join actors of the reverse chain, who since 2010 had differed on the format of WEEE RL, around a common goal in a cooperative way.

Not all the PP results were positive however, as the WEEE collections were well below the expected volumes, showing that cooperation has to occur among all RL members including the final consumer, yet the scope of the PP only envisaged their participation at the time of collection, excluding them from the process of implementation and discussion. The problem of the non-involvement of this fundamental link in RL is amplified by the lack of culture and consumer awareness in regard to the importance of proper disposal, and the socioenvironmental risks that WEEE poses. It has been found that the consumer needs to be encouraged and made aware of the benefits of proper disposal, so that he is motivated to participate in RL along with the other actors. The results of the PP showed the importance of creating motivational mechanisms for the consumer, with a significant increase in the amount 
of WEEE discarded in the last months of the PP, in a period where there was a massive campaign to publicise 'Black Friday' along with the incentive to discard EEE. This will require a synergised effort among the actors. Industry and retail must motivate consumer participation in RL with education and incentives. The government must legislate in favour of the feasibility of this chain and promote the RL market of WEEE with fiscal and financial incentives for its consolidation.

The presented research highlights the importance of cooperation as an essential element for the effectiveness of the RL of WEEE, since its complexity demands joint solutions. In this context, the research contributes to the understanding of the importance of building a well-defined structure, with clear roles and results, as well as a monitoring mechanism to ensure trust among all the actors involved in the partnership. In addition, it is important to ensure that all stakeholders, including the final consumer, are aware of the opportunities, benefits, and results, to achieve this partnership in WEEE RL.

\section{REFERENCES}

[1] Baldé, C.P. et al., E-waste statistics: Guidelines on classifications, reporting and indicators, United Nations University, IAS-SCYCLE, Bonn, Germany, 2015.

[2] Eurostat, Overview. http://ec.europa.eu/eurostat/about/overview. Accessed on: 16 Nov. 2016.

[3] Ylä-Mella, J. et al., Overview of the WEEE Directive and its implementation in the Nordic countries: national realisations and best practices. Journal of Waste Management, 2, 2014.

[4] Hischier, R., Wäger, P. \& Gauglhofer, J., Does WEEE recycling make sense from an environmental perspective? The environmental impacts of the Swiss take-back and recycling systems for waste electrical and electronic equipment (WEEE). Environmental Impact Assessment Review, 25, pp. 525-539, 2005.

[5] Khetriwal, D.S., Kraeuchi, P. \& Widmer, R., Producer responsibility for e-waste management: key issues for consideration and learning from the Swiss experience. Journal of Environmental Management, 90(1), pp. 153-165, 2009.

[6] Torretta, V., Ragazzi, M., Istrate, I.A. \& Rada, E.C., Management of waste electrical and electronic equipment in two EU countries: A comparison. Waste Management, 33(1), pp. 117-122, 2013.

[7] Wang, F., Huisman, J., Meskers, C.E., Schluep, M., Stevels, A. \& Hagelüken, C., The Best-of-2-Worlds philosophy: Developing local dismantling and global infrastructure network for sustainable e-waste treatment in emerging economies. Waste Management, 32(11), pp. 2134-2146, 2012.

[8] Augusto, E.E.F., Logística reversa de computadores e celulares: Desafios e perspectivas para o modelo brasileiro. Master's dissertation, University Center of FEI, São Paulo, Brazil, 2014.

[9] Vieira, J.G.V., Avaliação do estado de colaboração logística entre indústria de bens de consumo e redes de varejo supermercadista. Doctor thesis, University of São Paulo, São Paulo, SP, Brazil, 2006.

[10] Brazil, Lei $\mathrm{N}^{\circ}$ 12.305, de 2 de Agosto de 2010. Brasília, DF, 2010. http://www.planalto.gov.br/ccivil_03/_Ato2007-2010/2010/Lei/L12305.htm. Accessed on: 16 Jan. 2016.

[11] Winckler, N.C. \& Molinari, G.T., Competição, colaboração, cooperação e coopetição: revendo os conceitos em estratégias interorganizacionais. Revista ADMpg Gestão Estratégica, 4(1), pp. 1-12, 2011. 
[12] Drury, J.C., Consumers' Cooperation. The Journal of Marketing, 1(4), pp. 385-389, 1937.

[13] Gault, E.H., Cooperation by business groups. The Journal of Marketing, 1(4), pp. 396400, 1937.

[14] Kolbus, D., Building a collaborative advantage. Work Study, 41(1), pp. 10-15, 1992.

[15] Polenske, K., Competition, collaboration and cooperation: an uneasy triangle in networks of firms and regions. Regional Studies, 38(9), pp. 1029-1043, 2009.

[16] Da Silva, D.H., Cooperação internacional em ciência e tecnologia: oportunidades e riscos. Revista Brasileira de Política Internacional, 50(1), pp. 5-28, 2007.

[17] Hord, S.M., Working Together: Cooperation or Collaboration? Educational Resources Information Center (ERIC), 1981. http://files.eric.ed.gov/fulltext/ED226450.pdf. Accessed on: 12 Sep. 2016.

[18] Rogers, D.S. \& Tibben-Lembke, R.S., Going backwards: reverse logistics trends and practices, University of Nevada e Reverse Logistics Executive Council, Reno, 1998.

[19] Demajorovic, J., Augusto, E.E.F. \& De Souza, M.T.S., Reverse logistics of WEEE in developing countries: challenges and perspectives for the Brazilian model. Ambiente \& Sociedade, 19(2), pp. 119-137, 2016.

[20] Sinha-Khetriwal, D., Kraeuchi, P. \& Schwaninger, M., A comparison of electronic waste recycling in Switzerland and in India. Environmental Impact Assessment Review, 25, p. 492, 2005.

[21] Lau, K.H. \& Wang, Y., Reverse logistics in the electronic industry of China: a case study. Supply Chain Management: An International Journal, 14(6), pp. 447-465, 2009.

[22] SENS, SWICO, SLRS. Technical Report 2016, Online. http://www.swicorecycling. ch/downloads/dokumente/technical-report-2016.pdf/3837. Accessed on: 24 May 2016.

[23] Yin, R.K., Estudo de caso: planejamento e métodos, Bookman Porto: Alegre, 2005.

[24] Bardin, L., Análise de conteúdo, Almedina: São Paulo, 2011. 